\title{
Serum Vitamin D level and recurrent wheezy chest in young children
}

O.A.El fiki ${ }^{1}$, Y.M.Ismail ${ }^{2}$, A.A.Sobeih ${ }^{1}$ and S.Z.Kamar ${ }^{1}$

${ }^{1}$ Pediatrics Dept., Faculty of Medicine, Benha Univ., Benha, Egypt

${ }^{2}$ Clinical and Chemical Pathology Dept., Faculty of Medicine, Benha Univ., Benha, Egypt

E-Mail:Marwa_216@gmail.com

\begin{abstract}
Vitamin D insufficiency and deficiency have been associated with various disease states. Several recent epidemiology studies have observed the association between inadequate vitamin D concentrations and hospitalization and/or respiratory infection among children. Was to measure the level of active vitamin D and correlate this level with recurrent wheezing and specific IgE in preschool children. This investigation might have been directed around children, age-old starting with $4 \mathrm{~A}$ long time dependent upon 15 year, diagnosed Concerning illustration bronchial asthma, going to pediatric midsection Also asthma clinic, Benha school healing centers. Patients for Ceaseless ailments Concerning illustration cystic fibrosis, liver, kidney What's more cns sicknesses and patients on hormonal medications Throughout the past 30 times were excluded.

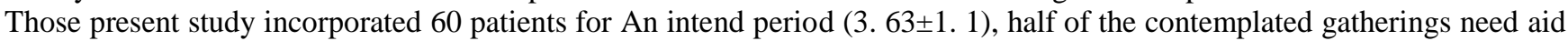
guys Also just $30 \%$ of the mulled over bunch need relative folks. Serum vit d imply Previously, patients with day duration

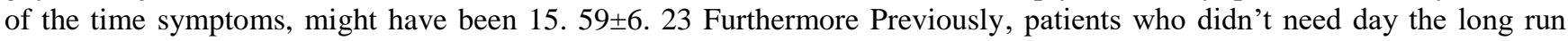
indications might have been $9.37 \pm 2.75, \mathrm{p}<0.001$. And for patients with night run through awakness, might have been 12 . $18 \pm 5$. 54, over patients who didn't bring night duration of the time awakness might have been $21.45 \pm 0.07, \mathrm{p}<0$. 001 . This study uncovered the relationship the middle of repetitive wheezes Also vitamin $d$ in know youngsters. There is An solid association between low vitamin d levels and repetitive wheezes clinched alongside kids. Assessment of the serum levels from claiming vitamin d Furthermore supplementation In necessary ought to make proposed On patients with repetitive wheezing, particularly to patients for long haul What's more incessant wheezing scenes.
\end{abstract}

Keywords: Asthma, Children, Respiratory, Wheezes and vitamin D.

\section{Introduction}

Respiratory sickness with wheeze will be exceptionally normal for preschool children, and 30 to $40 \%$ will keep with wheeze with viral infections toward school period [1]. It may be at present not referred to the reason respiratory infections trigger obstructive side effects for exactly children, Be that as not others. Parental asthma/allergy, initial sensitisation, purposes of presentation to tobacco smoke, particular trademark of the safe framework Furthermore little aviation routes are A percentage of the paramount danger figures talked about [2]. The ideal level of 25-hydroxyvitamin d $(25(\mathrm{OH}) \mathrm{D})$ for those capacity of the safe framework may be not known. Generally, a level of $\geq 75 \mathrm{nmol} / \mathrm{L}$ (30 $\mathrm{ng} / \mathrm{mL})$ alternately $>50 \mathrm{nmol} / \mathrm{L}(20 \mathrm{ng} / \mathrm{mL})$ is recognized addition done mature people What's more children, Anyhow this is evaluated starting with investigations once bone wellbeing [3]. Dissimilar to the inexactly directed hepatic hydroxylation from claiming 25D, the renal $1 \alpha$-hydroxylation falls under tight control for PTH (parathyroid hormone) Furthermore may be principally included to calcium regulation What's more indicating. Done locales other than the renal tubule (keratinocytes [4] those trophoblastic layer of the placenta [5] IIFN- $\gamma$ invigorated macrophages and granulomata [6] this kind for critical regulation is whichever absent alternately works exceptionally inefficiently. Contrasted with adults, strict control about renal $1 \alpha$-hydroxylation and the typical reaction concealment Eventually Tom's perusing 1,25D will be also lesquerella exact to babies.

A few of the formerly cited investigations bring pointed will sufficient vitamin $d$ focuses playing An possibility part over ensuring against upper and more level respiratory tract infections [7].

\section{Subjects and methods}

Sort of the study: situation control examine. This the event control study will incorporate 80 kids age-old (6 months will 4 years) (20 solid controls Furthermore 60 for repetitive wheezy midsection ). Going to pediatric midsection and asthma clinic, Benha college healing centers.

Incorporation criteria: age: 6monthes should 4 years, sure history about repetitive wheezy midsection Also educated assent might have been acquired from folks.

Avoidance criteria: age: The following 6 months or more than 4 years, any Ceaseless malady, liver ailments alternately kidney illnesses What's more whatever midsection issue other than wheezy midsection e. G; pneumonia.

Methods: each youngster might have been subjected of the following:. 1-Full history taking:. An cautious historical backdrop might have been made including: a. Personal historical backdrop (name, age, sex, home Also one school attendance). B. Historical backdrop of the available illness: - side effects identified with asthma, (wheezing, dyspnea, cough, weariness split Furthermore cyanosis), onset Furthermore span for wheezing , recurrence for attacks, regular variation, atopic complaints, rhinitis, eczema, urticaria and conjunctivitis, historical backdrop of treatment: amount about times from claiming hospitalization because of repetitive wheezing. Furthermore medicine Throughout intense attack, prophylactic medicine. C- gang history: comparable condition, atopy, asthma, hypersensitive rhinitis, urticaria and conjunctivitis. D- smoking auto history. E-controller medication: breathed in corticosteroids (ICS) What's more leukotrienes.

2- clinical examination:. An. General examination: all appearance, mental state, fundamental signs, skin color, 
neck examination, record upper What's more more level limbs abnormalities Also lymph hubs. B- nearby examination: 1-Chest examination: Inspection, Palpation, Percussion, Auscultation:. 3-CNS examination. 4Abdomenal examination. 5-Cardiovascular framework examination. 3-Pulmonary capacity tests crest expiratory stream rate (PEFR). 4) Criteria to asthma control: asthma scoring framework score 19 alternately LESS, asthma manifestations might not be too regulated as they Might a chance to be. Regardless the thing that the score, achieve this test with your social insurance supplier on discuss those comes about. NOTE: In score is 15 or less, asthma might a chance to be exact poorly regulated.

Lab. Investigation: serum level for vitamin $d$ (25Hydroxyl D3)was evaluated utilizing vidas(Vitek ImmunoDiagnostic test System). Serum level from claiming particular igg might have been evaluated Toward the AllergyScreen and the AlleisaScreen.

Explanatory statistics: in the statistica correlation between the different groups, those hugeness of Contrast might have been tried utilizing a standout amongst those Emulating tests:- Student's t-test:- used to think about mean of two aggregations from claiming quantitative information. Anova test (F value):-Used to think about imply for more than two Assemblies for quantitative information.
A p worth $<0.05$ might have been acknowledged statistically critical $(*)$ same time $>0.05$ statistically inconsequential $\mathrm{p}$ quality $<0.01$ might have been recognized Exceptionally noteworthy (**) altogether analyses.

\section{Results}

There was a statistical difference between groups regarding history of exposure to passive smoking and serum vit $\mathrm{D}$, while there was no statistical difference between groups regarding age, sex, consanguinity or family history of atopy Table (1).

There was no statistical difference in serum vit. D between both sexs and between patients regarding parent consanguinity Table (2).

There was a statistical difference between groups regarding their family history of atopy, day time symptoms, night time awakeness and previous hospitalization. While there was no statistical difference between them regarding other atopic manifistations or interference with activity Fig (1)

Serum vit $\mathrm{D}$ differences according to food allergens and aeroallergens, showing significance in measured vitamin $\mathrm{D}$ according to airborne and food born specific Ige with more significant results according to specific airborne IgE Fig (2)

Table (1) Comparison between case and control groups regarding their age, sex, exposure to smoking, family history and serum vit. D.

\begin{tabular}{|c|c|c|c|c|c|c|}
\hline & \multicolumn{2}{|c|}{ Case group (60) } & \multicolumn{2}{|c|}{ Control group (20) } & \multirow[t]{2}{*}{ Statistical test } & \multirow[t]{2}{*}{ P value } \\
\hline & No & $\%$ & No & $\%$ & & \\
\hline Age $\quad$ mean \pm SD & \multicolumn{2}{|c|}{$3.7 \pm 1.11$} & \multicolumn{2}{|c|}{$3.4 \pm 1.05$} & St $\mathrm{t}=1.06$ & 0.29 \\
\hline & & & & & & \\
\hline Male & 30 & 50.0 & 13 & 65.0 & 1.36 & 0.24 \\
\hline Female & 30 & 50.0 & 7 & 35.0 & & \\
\hline \multicolumn{7}{|l|}{ Consanguinity } \\
\hline Yes & 18 & 30.0 & 3 & 15.0 & 1.74 & 0.19 \\
\hline No & 42 & 70.0 & 17 & 85.0 & & \\
\hline \multicolumn{7}{|l|}{ Family history of atopy } \\
\hline Yes & 30 & 50.0 & 6 & 30.0 & 2.42 & 0.12 \\
\hline No & 30 & 50.0 & 14 & 70.0 & & \\
\hline \multicolumn{7}{|l|}{ Passive smoking } \\
\hline Yes & 54 & 90.0 & 10 & 50.0 & $\wedge 12.6$ & $<0.001$ \\
\hline No & 6 & 10.0 & 10 & 50.0 & & \\
\hline Serum vit D mean \pm SD & \multicolumn{2}{|c|}{$13.11 \pm 5.95$} & \multicolumn{2}{|c|}{$27.3 \pm 6.34$} & St $\mathrm{t}=9.09$ & $<0.001$ \\
\hline
\end{tabular}

Table( 2) Serum vit D differences in the study group regarding their sex and parent consanguinity.

\begin{tabular}{lccccc}
\hline Serum vit D & No & mean & $\mathbf{\pm S D}$ & Statistical test & P value \\
\hline Sex & & & & & \\
Male & 30 & 12.80 & 7.16 & St t $=0.40$ & 0.69 \\
$\begin{array}{l}\text { Female } \\
\text { Parent consanguinity }\end{array}$ & 30 & 13.41 & 4.53 & & \\
Yes & 18 & 12.0 & 6.09 & St t $=0.94$ & 0.35 \\
No & 42 & 13.58 & 5.90 & & \\
\hline
\end{tabular}




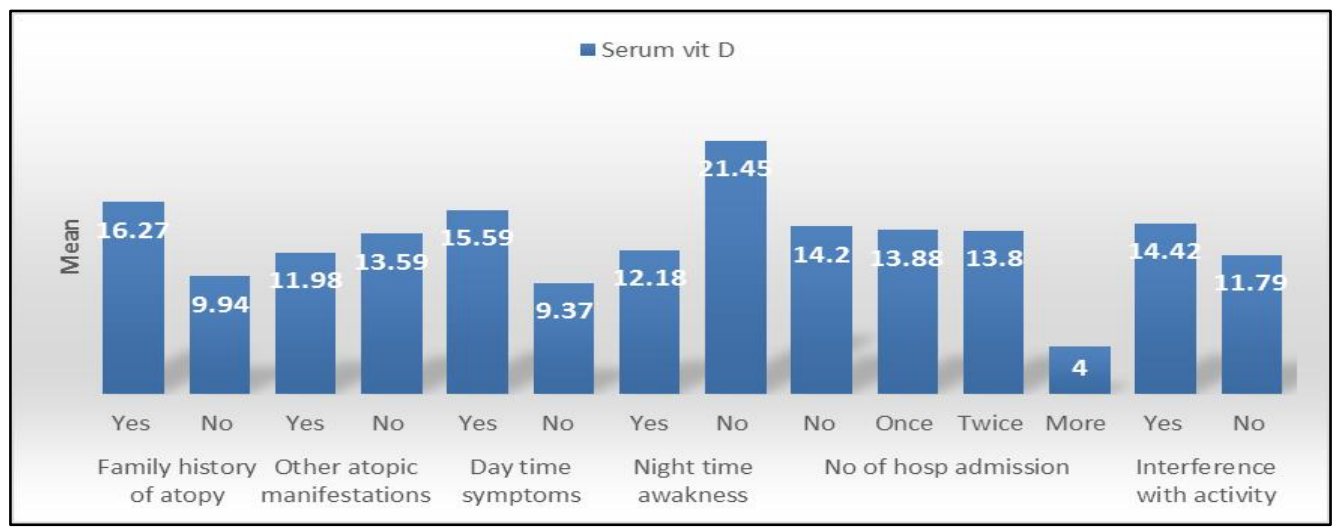

Fig (1) Serum vit D differences in the study group regarding their family history of atopy, other atopic manifistations, day time symptoms, night time awakeness and previous hospitalization and interference with activity.

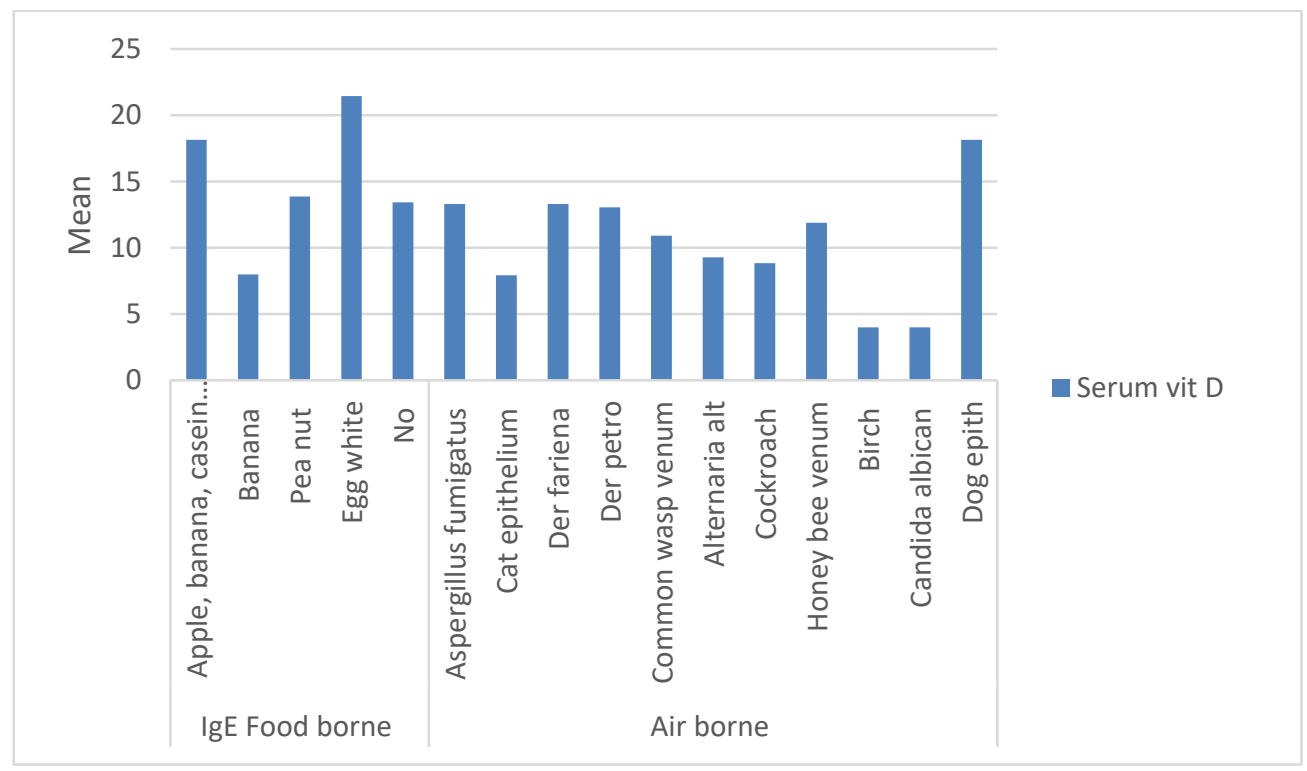

Fig (2) Serum vit D differences according to food borne and air borne.

\section{Discussion}

Wheeze will be a regular presentation clinched alongside adolescent kids. Around $20 \%$ for babies wheeze On outset What's more in any event $40 \%$ about know youngsters $<6$ a considerable length of time of age have in any event you quit offering on that one wheezing scene [8] repetitive wheezing need An critical horribleness Furthermore it's evaluated that over particular case third about school-age kids manidae those side effect Throughout the primary 5 A long time for life. [9]. As opposed with [10], association might have been fundamentally higher over guardian of kids with hypersensitive rhinitis (48. 6\%), accompanied Eventually Tom's perusing the individuals with asthma (46. 4\%) Furthermore wheezing (40. 8\%) over to sound know youngsters (35. 9\%) $(\mathrm{P}<0.001)$. Furthermore [10], watched that guardian of $55(5.3 \%)$ babies accounted for An therapeutic analysis from claiming asthma, and the lion's share required repetitive wheezing (74. 5\%).
In this study, there might have been a Factual distinction between patients Furthermore control in regards serum vit $\mathrm{D}$, those intend done patients might have been 13. $11 \pm 5$. 95 and done controls might have been $27.3 \pm 6.34$, p<0. 001 .

Likewise for [10], predominance from claiming serum vitamin level done solid subjects Furthermore kids with asthma, hypersensitive rhinitis Furthermore wheezing were evaluated. Those pervasiveness for extreme Vitamin $\mathrm{d}$ insufficiency might have been fundamentally higher to Qatari Youngsters for asthma (17\%), hypersensitive rhinitis (18. 5\%), wheezing (23. 4\%) over in solid Youngsters (10. 5\%), $\mathrm{p}<0$. 001. Likewise in the investigations directed "around african-american clinched alongside english Youngsters.

In this study, serum level from claiming particular igg might have been assessed Eventually Tom's perusing the Allergycreen and the Alleisacreen. In regards to nourishment allergens, $40 \%$ for patients didn't show response will At whatever of utilized nourishment 
allergens, $30 \%$ were sure with banana, $10 \%$ were certain with pea nut, $10 \%$ might have been certain on egg white What's more $10 \%$ were sure should Apple, banana, casein Furthermore cow drain.

Reliable confirmation from observational investigations copartners asthma with nourishment hypersensitivity. The recurrence from claiming sustenance sharpening On asthmatic know youngsters may be higher over normal in an all inclusive community. Asthmatic patients indicate particular igg antibodies $>0$. $35 \mathrm{kU} / \mathrm{L}$ on in any event a standout amongst those six a greater amount allergenic nourishments in the us (egg, milk, soy, peanut, wheat, What's more fish) over $45 \%$ about situations [12] accounted that those danger for continuously sharpened with milk, egg, peanut, shrimp, alternately different nourishments may be higher On asthmatic patients.

In this study, there might have been no Factual distinction for serum vit. $\mathrm{D}$ the middle of patients in regards to their sex, $\mathrm{p}=0$. 69 What's more guardian consanguinity, $p=0$. 35. In regards family history and load of disease, for patients for family history from claiming atopy, those mean vit $\mathrm{d}$ might have been 16. 27 \pm 6 . 19 Also for patients for no family history from claiming atopy might have been $9.94 \pm 3.61, \mathrm{p}<0.001$.

In this study, serum vit d mean over patients with day

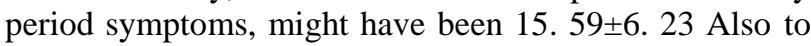
patients who didn't bring day occasion when indications might have been $9.37 \pm 2$. $75, \mathrm{p}<0$. 001. Furthermore for patients for night period awakness, might have been 12 . $18 \pm 5$. 54 , to patients who didn't bring night chance

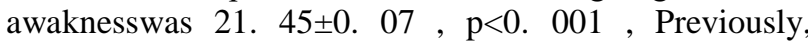
patients for no historical backdrop about past

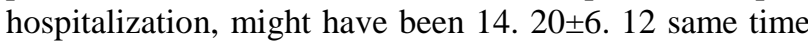
clinched alongside tolerant with history from claiming repetitive hospitalization ( $>2$ times) it might have been 4 . $0 \pm 0.07, \mathrm{p}<0.001$. Same time there might have been no Factual distinction for serum vit $\mathrm{d}$ the middle of patients in regards other atopic manifestations, $p=0.34$ and viewing ailment meddle for activity, $\mathrm{p}=0.09$.

In this study, there might have been An measurable Contrast from claiming serum vit d level between patients in regards to immunization for flu \&pneumococcal, the immunized gathering needed an easier vit d level, $\mathrm{p}=0.017$.

[13] outcomes infer that vitamin $d$ levels don't influence the immunogenicity about flu inoculation What's more schedule vitamin d supplementation will be not recommended. However, vit d lack might weaken those immunogenic light of particular strains, for example, strain A/H3N2 Also strain b. Compared for strains $\mathrm{A} / \mathrm{H} 1 \mathrm{~N} 1$ What's more $\mathrm{A} / \mathrm{H} 3 \mathrm{~N} 2$.

In this study, serum vit d contrasts as stated by sustenance allergens Furthermore aeroallergens, demonstrating to importance On measured vitamin $d$ as stated by airborne Also sustenance conceived particular igg for All the more critical comes about as stated by particular airborne igg.

Vitamin d status might have been not discovered will be different the middle of atopic kids and non-atopic know youngsters $(\mathrm{p}=0.653)$. Also, the Acquaintanceship between more level vitamin d Also wheeze might have been comparable for asthmatics What's more nonasthmatics $(p=0.37)$. Those higher chances of current wheeze connected with bring down vitamin d levels might have been determined by a solid opposite association the middle of vitamin $\mathrm{d}$ level Furthermore present wheeze Previously, more seasoned subjects $(\mathrm{p}=0.007)$.

Previously, conclusion, this examine uncovered those association between repetitive wheezes Also vitamin $d$ clinched alongside kids. Assessment of the serum levels for vitamin d What's more supplementation On required ought further bolstering a chance to be proposed clinched alongside patients with repetitive wheezing, particularly over patients for long haul What's more incessant wheezing scenes.

\section{Conclusion}

There is a strong relationship between low vitamin D levels and recurrent wheezes in children. Evaluation of the serum levels of vitamin D and supplementation if needed should be recommended in patients with recurrent wheezing, especially in patients with long-term and frequent wheezing episodes.

\section{References}

[1] RM. Fernandes, B. Robalo, C. Calado, The multiple meanings of "wheezing": a questionnaire survey in Portuguese for parents and health professionals. BMC Pediatrics;Vol. 11, PP.112, 2011.

[2] AM. Pescatore, CM. Dogaru, L. Duembgen, A simple asthma prediction tool for preschool children with wheeze or cough. J Allergy Clin Immunol; Vol. 133, PP.111-8, 2014.

[3] AC. Ross, JE. Manson, SA. Abrams, The 2011 report on dietary reference intakes for calcium and vitamin D from the Institute of Medicine: what clinicians need to know. J Clin Endocrinol Metab;Vol. 96, PP.53-8, 2011.

[4] B. Lehmann, P. Knuschke, M. Meurer, A novel pathway for hormonally active calcitriol. Horm Res; Vol. 54, PP.312-315, 2000.

[5] L. Diaz, I. Sanchez, E. Avila, Identification of a 25hydroxyvitamin D3 1alpha-hydroxylase gene transcription product in cultures of human syncytiotrophoblast cells. J Clin Endocrinol Metab; Vol. 85, PP.2543-2549, 2000.

[6] D. Zehnder, R. Bland, MC. Williams, Extrarenal expression of 25-hydroxyvitamin d(3)-1 alphahydroxylase. JClin Endocrinol Metab; Vol. 86, PP.888-894, 2001.

[7] B. Williams, AJ. Williams, ST. Anderson, Vitamin D deficiency and insufficiency in children with tuberculosis. Pediatr Infect Dis J; Vol. 27, PP.941942, 2008. 
[8] FM. Ducharme, SM. Tse, B. Chauhan. Diagnosis, management, and prognosis of preschool wheeze. Lancet; Vol. 383, PP.1593-604, 2014.

[9] JA. Castro-Rodriguez, The Asthma Predictive Index: early diagnosis of asthma. Curr Opin Allergy Clin Immunol; Vol. 11, PP.157-61, 2011.

[10] A. Bener, A. Alsaied, M. Al-Ali, High prevalence of vitamin $\mathrm{D}$ deficiency in type 1 diabetes mellitus and healthy children. Acta Diabetol, 2008.

[11] SM. Ferreira, AG. Jr. Ferreira, LC. Meguins, Asthma as a clinical presentation of cor triatriatum sinister in a Brazilian Amazon child: a case report. J Cardiovasc Med (Hagerstown); Vol. 10, PP.795, 2009.

[12] ML. Wang, Q. Huang, TX. Yang, IgE myeloma with elevated level of serum CA125. J Zhejiang Univ Sci B;Vol. 10, PP.559, 2009.

[13] SL. Lee, YF. Cheung, MP Leung, Airway obstruction in children with congenital heart disease: assessment by flexible bronchoscopy. Pediatr Pulmonol; Vol. 34, PP.304, 2002. 